Original article

\title{
Vitamin D deficiency and associated factors among pregnant women of a sunny city in Northeast of Brazil
}

\author{
Marcos Pereira-Santos a, *, Gisele Queiroz Carvalho ${ }^{b}$, Ricardo David Couto ${ }^{\text {, }}$ \\ Djanilson Barbosa dos Santos ${ }^{\mathrm{d}}$, Ana Marlucia Oliveira ${ }^{\mathrm{e}}$ \\ ${ }^{a}$ Universidade Federal do Oeste da Bahia, Center of Biological and Health Sciences, Campus Reitor Edgard Santos, Barreiras, Bahia, Brazi \\ ${ }^{\mathrm{b}}$ Universidade Federal de Juiz de Fora, Campus Governador Valadares, Minas Gerais, Brazil \\ ${ }^{\text {c } U n i v e r s i d a d e ~ F e d e r a l ~ d a ~ B a h i a, ~ F a c u l d a d e ~ d e ~ F a r m a ́ c i a, ~ S a l v a d o r, ~ B a h i a, ~ B r a z i l ~}$ \\ ${ }^{\mathrm{d}}$ Universidade Federal do Recôncavo da Bahia, Center for Health Sciences, Santo Antônio de Jesus, Bahia, Brazil \\ e Universidade Federal da Bahia, School of Nutrition, Salvador, Bahia, Brazil
}

\section{A R T I C L E I N F O}

\section{Article history:}

Received 27 May 2015

Accepted 22 September 2017

\section{Keywords}

Pregnant women

Vitamin D

Vitamin D deficiency

Sun exposure

Maternal nutrition

\begin{abstract}
S U M M A R Y
Objective: We analyzed the serum vitamin $\mathrm{D}$ concentrations and identified the factors associated with vitamin $\mathrm{D}$ deficiency in Brazilian pregnant women, in a city with a high solar exposure.

Methods: Cross-sectional study with a sample of 190 pregnant women in a municipality in the Brazilian state of Bahia. Socio-environmental information, regarding the lifestyle and biological factors of participants, was collected and recorded in a questionnaire, and serum concentrations of 25(OH)D was determined (PR).

Results: The deficient and insufficient vitamin D concentrations were found in $14.21 \%$ and $44.74 \%$ of the pregnant women, respectively. Vitamin D deficiency was associated with commuting to work via motor vehicles (PR: 2.79; 95\% CI: 1.06-7.31), with winter (prevalence ratio - PR: 1.54; 95\% CI: 1.01-2.35), exposure to the sun only on the face and hands (PR: 2.99; 95\% CI: 1.35-6.63) and single pregnant women (PR: 2.53; 95\% CI: 1.01-6.35).

Conclusions: We detected a high proportion of pregnant women with vitamin deficient and insufficient vitamin $\mathrm{D}$ levels among pregnant women of a sunny city. These data suggest the necessity to monitor serum vitamin D levels during pregnancy and the adequate orientation in prenatal care to adoption healthy lifestyle for the prevention of vitamin D deficiency in this population.
\end{abstract}

@ 2017 European Society for Clinical Nutrition and Metabolism. Published by Elsevier Ltd. All rights reserved.

\section{Introduction}

Pregnancy is a phase of life that is susceptible to vitamin D deficiency, since the demand for this nutrient increases; not only to meet the needs of the pregnant and maintain their own reserves, but also to meet the demands of the fetus [1].

Vitamin D performs functions in the regulating of cell differentiation and in the development of the immune system and brain [2], in addition to consist in placental calcium transport and acting in its homeostasis; thereby regulating the fetal osteogenesis process. In this sense, the deficiency of this vitamin during pregnancy may affect the development and growth of the fetus [3].

\footnotetext{
* Corresponding author. Rua Professor José Seabra de Lemos, 316, Recanto dos Pássaros, CEP: 47808-021 Barreiras, Bahia, Brazil.
}

E-mail address: pereira-santosm@bol.com.br (M. Pereira-Santos).
Vitamin D deficiency is associated with adverse health problems in pregnancy such as the occurrence of preeclampsia, genitourinary infections, and gestational diabetes, as well as the risk of a caesarean section [2,3]. Moreover, inadequate vitamin D concentrations during pregnancy may increase the risk of health problems to newborns, including low weight, small birth size for the gestational age [3-5] and in later life could result in the risk of food allergies [6] asthma, rickets [7] and endocrine metabolic diseases [8].

Thus, scientific effort has been undertaken to identify factors associated with vitamin D deficiency in pregnant women, with special attention paid to the environmental and individual factors. Among the environmental factors, there are high air pollution, high latitude, the period of winter and the duration of sun exposure [9]. In regards to the individual factors, studies identify obesity $[10,11]$, black skin color [9] and metabolic disorders, as in the example of primary hyperparathyroidism and renal or hepatic insufficiency, as 
important risk factors of vitamin D deficiency [8,9], as well as the low education level [12] and low income of the mother $[13,14]$.

In reference to the bioavailability of vitamin $\mathrm{D}$, it is estimated that $80-90 \%$ of the $25(\mathrm{OH}) \mathrm{D}$ circulating in the human body is derived from sun exposure and the remainder is provided by food, with the most significant sources being butter, cheese, eggs and fish oil [15].

Thus, in regions with low latitude, it is possible to photosynthesize this vitamin in adequate concentrations during all seasons of the year, due to the availability of UV rays - UVB [16]. Paradoxically, studies of the populations of countries with tropical climate, such as Brazil, record a high prevalence of vitamin D deficiency among different age groups $[17,18]$. However, it was not identified in the literature study on the prevalence and determinants of vitamin D deficiency in pregnant Brazilian women. In addition, most of the available research on this group is carried out in countries with low solar presence [19]. Thus, the aim of this study is to analyze the serum concentrations of vitamin D and identify the factors associated with vitamin D deficiency among pregnant Brazilian woman in a city with high sun exposure.

\section{Materials and methods}

\subsection{Population and sample}

A cross-sectional study nestled to one cohort of pregnant women "Factors of nutritional and genetic risk during pregnancy associated with low birth weight/prematurity - NISAMI Study", conducted in Santo Antonio de Jesus a municipality of Northeast of Brazil, with a land area of $261 \mathrm{~km}^{2}$, lying $187 \mathrm{~km}$ from the city of Salvador, the capital of the state of Bahia. It is located at $12^{\circ} 58^{\prime} \mathrm{S}, 36^{\circ} 16 \mathrm{~W}$, with a tropical climate (annual average of $23.0^{\circ} \mathrm{C}$ ), with a high solar radiation daily average $\left(11.8 \mathrm{MJ} / \mathrm{m}^{2}\right.$, maximum of 22 in January $\mathrm{MJ} / \mathrm{m}^{2}$ and minimum of $12 \mathrm{MJ} / \mathrm{m}^{2}$ in June) and annual average of daily isolation of $7 \mathrm{~h}[20,21]$. Seasons of the year were defined as summer (December-January-February), fall (March-April-May), winter (June-July-August) and Spring (September-October-November).

To identify factors associated with vitamin D concentrations, a sample of 161 with a women was calculated, using the prevalence of $73.5 \%$ of hypovitaminosis $\mathrm{D}[25(\mathrm{OH}) \mathrm{D}<80 \mathrm{nmol} / \mathrm{L}]$ in normal weight pregnant women [11],with an estimated variation of $10 \%$ in these concentrations, depending on the geographic location of the municipality in question. A type I error $(\alpha)$ was adopted of $5 \%$, and to the power of $80 \%$. However, for this study, effectively 190 pregnant women were investigated.

This study was approved by the ethics committee of the School of Nutrition, Federal University of Bahia (UFBA).

\subsection{Eligibility criteria and data collection}

Clinically healthy women with 18 years or more of age, resident and domiciled in the urban area Northeast of Brazil were included in this study. The eligibility criteria to participate were a gestational age of less than 32 weeks at the time of first contact and attending the service of prenatal care of the public health system (SUS). Women with multiple pregnancies, preeclampsia, kidney problems, HIV and women who had not fasted for the blood collection were excluded. However, these conditions were not identified among the selected pregnant women.

Trained interviewers collected the data and information relating to the socioeconomic and demographic conditions, lifestyle and sun exposure habits were recorded in a standardized questionnaire.

The pre-pregnancy weight collected from the health card of the pregnant woman and, if not available, the reported weight was used. Height was measured in the health unit, by the health service team, according to Lohman et al.'s [22] recommendations. The gestational age at the time of blood collection was calculated based on the last menstrual period available on the card of the pregnant woman or by recording the gestational age at the time of the first ultrasound performed until the end of the first trimester.

\subsection{Serum 25-hydroxyvitamin D measurement}

The blood collection was performed in the morning, between 7:00 am and 9:00 am, adopting a fasting period of at least $8 \mathrm{~h}$. On the day before blood collection, the pregnant woman was reminded by telephone about the date and time and the guidance on the blood collection. At the laboratory, the trained technician performed the collection of $6 \mathrm{ml}$ of blood with a vacuum tube, brand BD Vacutainer ${ }^{\circledR}$, for determination of $25(\mathrm{OH}) \mathrm{D}$, total calcium and blood count.

After collection, the blood was centrifuged for $15 \mathrm{~min}$ at $2000 \mathrm{rpm}$, in an environment with low light for serum separation. The serum samples were identified by codes and stored at $-32^{\circ} \mathrm{C}$ in a freezer, until the time of measurement of 25(OH)D. For this, we used the quantitative determination method, based on the principle of chemiluminescence (CLIA). The dosage kit of 25(OH)D (DiaSorin ${ }^{\circledR}$ ) was used; with a intra-assay coefficient of variation (CV) of $8.4 \%-12.5 \%$ and an inter-assay CV of $8.6 \%-11.0 \%$.

The blood count was performed with the equipment Sismex XT $1800 \mathrm{i}^{\circledR}$ and the total calcium was measured by the chemical analysis Vitros (Johnson \& Johnson ${ }^{\circledR}$ ).

\subsection{Response variables and exposure}

The serum concentration of $25(\mathrm{OH}) \mathrm{D}$ was defined as the response variable and classified as low ( $<50 \mathrm{nmol} / \mathrm{L})$, insufficient $(\geq 50 \mathrm{nmol} / \mathrm{L}$ and $75 \mathrm{nmol} / \mathrm{L}$ ) and sufficient ( $\geq 75 \mathrm{nmol} / \mathrm{L})$ [23]. In the multivariate analysis, the concentrations of $25(\mathrm{OH}) \mathrm{D}$ were categorized as deficient $(<50 \mathrm{nmol} / \mathrm{L})$ and not deficient $(\geq 50 \mathrm{nmol} /$ L).

The exposure variables are represented by sociodemographic, biological and health care conditions; including maternal age [18-29 years (0), $\geq 30$ (1)], family income [0-3 minimum wages per month (0), $\geq 4$ minimum wages per month (1)], maternal education ( $<11$ years of schooling ( 1$), \geq 11$ years of schooling ( 0$)$ ], skin color [no black-black (2)], marital status [married/partner) (0); unmarried, single (1)].

Among those biological, gestational age at blood collection [6-13 weeks (0); $\geq 13-26$ weeks (1)] were selected. Variables related to the habits and lifestyle were also adopted: number of times exposed to the sun per week $[\geq 4-6$ times a week (0), $<4$ times a week (1)], the body part that is exposed to the sun [Arms and legs (0), face and hands (1)], and the use of sunscreen [no (0) yes (1)].

\subsection{Statistical analysis}

The prevalence was adopted to describe the categorical variables, and for the continuous variables we adopted the average and standard deviation. The comparison of the mean concentrations of $25(\mathrm{OH}) \mathrm{D}$, in accordance with the exposure variables, was performed using a student's T-test for equal variances. The comparison between the prevalence of categorical variables of interest and vitamin D concentrations was performed using the chi-squared test. The variables that integrated the multivariate Poisson model were selected based on the backward technique [24], which consists of including all the variables in the model and selecting those that presented $\mathrm{p} \leq 0.20$ and, in the final model the associations were accepted with a value $\mathrm{p}<0.05$. The prevalence ratio (PR) was 
used as a measure of association, and the value $\mathrm{p}(<0.05)$ and the confidence interval were used to evaluate the magnitude of the association found. The analyses were performed using the Stata/IC program for Mac (Stata Corp, College Station), version 12.0].

\subsection{Ethical approval}

All procedures performed in studies involving human participants were in accordance with the ethical standards of the institutional research committee and with the 1964 Helsinki declaration and its later amendments or comparable ethical standards. Informed consent was obtained from all individual participants included in the study.

\section{Results}

The description of the characteristics of the 190 pregnant women sampled in this study is presented in Table 1 . The predominant age was of $18-29$ years (63\%) among those interviewed; low-income (65\%) and a level of education more or equal to 11 years of schooling (73\%). It was also observed that $43 \%$ of the group presented a pre-pregnancy BMI classified as overweight, anemia and hypocalcaemia reached $22 \%$ and $13 \%$ of the pregnant women, respectively.

The frequency of exposure to the sun of 4-6 times a week was identified in $39 \%$ (74) of the women, the habit of daily self exposure for up to $45 \mathrm{~min}$ to the sun was reported by $45.0 \%$ of them and the use of clothing that allowed the exposure of the upper limbs to the sun was reported by $73 \%$ (134) of the pregnant women. However, sunscreen was used daily by $51 \%$ (97) of them, being mostly (32\%) and only 5\% (9) were using a food supplement source of vitamin D (data not present in the table). The average of concentrations of $25(\mathrm{OH}) \mathrm{D}$ was $79(\mathrm{SD}=32) \mathrm{nmol} / \mathrm{L}$. The deficient and insufficient vitamin D concentrations were found in $14.2 \%$ and $44.7 \%$ of the pregnant women, respectively. The highest concentrations of this vitamin were observed during spring/summer $(90, S D=36 \mathrm{nmol} / \mathrm{L})$ and the lowest in winter (66, SD: $26 \mathrm{nmol} / \mathrm{L}$ ) (Fig. 1). During this season, the prevalence of vitamin D deficiency was 57\% (43), while in spring and summer, the prevalence was $34 \%$ (28) (data not shown). It was observed that $54 \%$ (102) of the women had some form of employment and 52\% (99) went to work on foot.

It was observed that pregnant women with a low concentration of vitamin D had a higher family income, a higher educational level, 2nd trimester, part of the body exposed to the sun, method of

Table 1

Sociodemographic characteristics of the pregnant women, Santo Antônio de Jesus, Bahia, Brazil, 2013-2014.

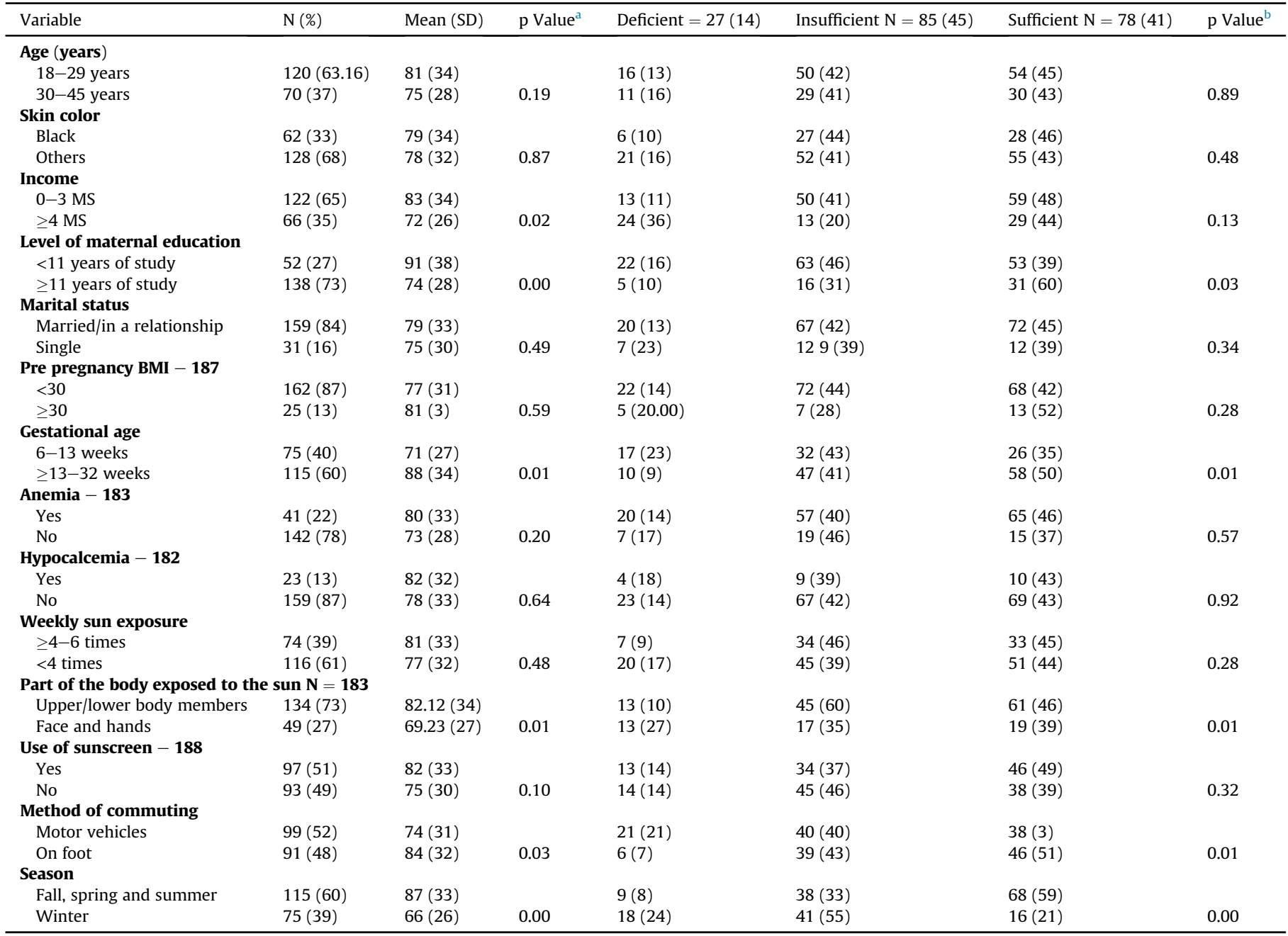

\footnotetext{
a Student's t-test.
}

b Chi-squared test. 


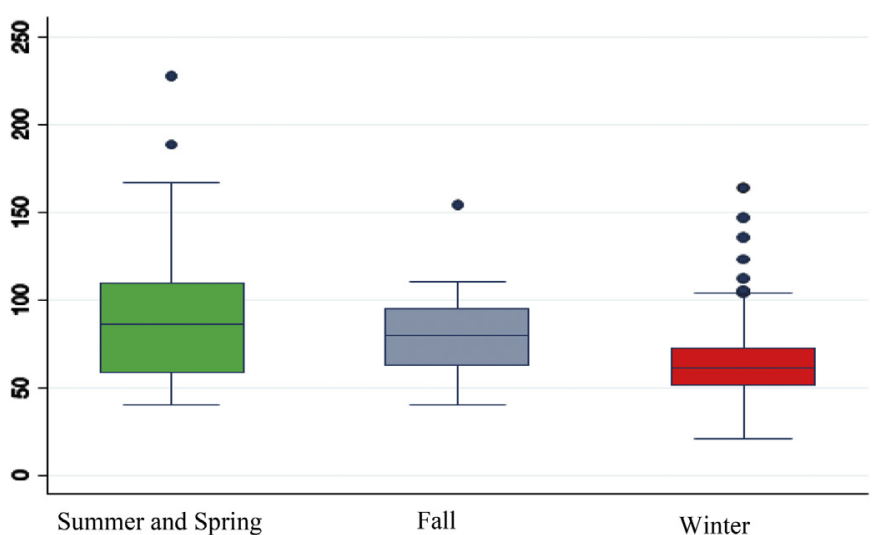

Fig. 1. Concentrations of 25(OH)D in pregnant women according to the seasons of the year, Santo Antônio de Jesus, Bahia, Brazil, 2013-14.

commuting and season $(\mathrm{p}<0.05)$. There were no statistically significant differences between deficient and not deficient average concentrations of 25(OH)D for the age of the pregnant women, prepregnancy BMI, serum hemoglobin and calcium concentration, exposure to the sun and use of Sunscreen (Table 1).

The results of the Poisson regression for the association between the selected determinants and deficient concentrations of $25(\mathrm{OH}) \mathrm{D}$ are shown in Table 2. It was found that vitamin D deficiency during pregnancy was associated with the marital status corresponding to pregnant women (PR: 2.5 ; 95\% CI: 1.01-6.35), sun exposure to only the hands and face (PR: 2.9; 95\% CI: 1.3-6.6), use of motor vehicles for commuting to work (PR: 2.8; 95\% CI 1.1-7.4) and winter (PR: 2.6; $95 \%$ CI: $1.1-7.3)$.

\section{Discussion}

The high prevalence of vitamin D insufficiency (45\%) and deficiency (14\%) among pregnant women living in a sunny geographical area in northeastern Brazil in this study follows the same trend, this observed in countries with a low exposure of sunlight. A similar result was recorded in pregnant women in Norway, $16.8 \%$ of disability and $34.0 \%$ and insufficiency of vitamin D [25]. Prevalence of lightly higher (27.4\% deficiency and insufficiency in $35.3 \%$ of pregnant women) were recorded in northern Spain [26]; and

Table 2

Vitamin D deficiency in pregnant women and associated factors, Santo Antônio de Jesus, Bahia, Brazil, 2013-2014. ${ }^{\text {a }}$

\begin{tabular}{lll}
\hline Variables & Unadjusted RP, ${ }^{\mathrm{b}}$ 95\% CI & Adjusted RP, 95\% CI \\
\hline $\begin{array}{l}\text { Marital status } \\
\quad \text { Married/in a relationship }\end{array}$ & 1 & \\
$\quad$ Single & $1.80(0.75-4.24)$ & $2.53(1.01-6.35)$ \\
Gestational age & & \\
$\quad 6-13$ weeks & 1 & $0.50(0.21-1.18)$ \\
$\quad \geq 13-32$ & $0.38(0.17 ; 0.83)$ & \\
Weekly sun exposure & 1 & $1.25(0.50-3.13)$ \\
$\quad \geq 4-6$ times & $1.82(0.77-4.31)$ & \\
$\quad<4$ times & 1 & $2.99(1.35-6.63)$ \\
Part of the body exposed to the sun & 1 \\
$\quad$ Upper/lower body members & 1 & $2.79(1.06-7.31)$ \\
$\quad$ Face and hands & $2.73(1.26-5.89)$ & \\
Method of commuting & 1 & 1 \\
$\quad$ On foot & $3.21(1.29-7.97)$ & $1.54(1.01-2.35)$ \\
$\quad$ Transport & 1 & \\
Season & & \\
$\quad$ Summer, Spring, Fall & $1.75(1.17-2.61)$ & \\
$\quad$ Winter & & \\
\hline a Poisson regression. & & \\
b Prevalence ratio (PR). & &
\end{tabular}

among pregnant women from Belgium, it was observed higher prevalence of $74 \%$ failure and $44.6 \%$ of vitamin D deficiency compared to our studies [27].

These are higher prevalence than in pregnant women with HIV residing in different countries in Latin America (30.5\% deficient and insufficient 35.2\%) [28]. In the city of Porto Alegre, Southern Brazil higher prevalences of vitamin D deficiency was diagnosed in $53.3 \%$ of the sample, and insufficiency was found in $33.2 \%$ of the pregnant women with diabetes [29].

On the other hand, we identify few studies in the literature reports regarding the vitamin D concentrations in Brazilian pregnant women, the studies carried out with adults, children and the elderly in different regions in Brazil report a high prevalence of vitamin $\mathrm{D}$ deficiency $[17,18,30]$. Based on these records, it can be suggested that the high prevalence of vitamin D deficiency can be influenced by the lifestyle of these population groups and the environment in which they live.

Among the factors associated with lifestyle, it was observed that the highest prevalence of vitamin D deficiency was observed among single mothers, when compared with those who were living with a partner. These results were also recorded in previous population-based studies in which the highest concentration of vitamin D in serum was observed among married women or those who had partners (married or cohabiting), which can be understood by the fact that married people could possibly spend more time outdoors and have a more balanced diet than singles [14,31].

In addition, the habit of exposing only the faces and hands to the sun was associated with vitamin D deficiency in pregnant women when compared to those who exposed the arms and legs to the sun. Accordingly, it is recognized that the use of long garments decreases the areas of skin exposed to sun rays, thus contributing to a lower level of synthesis of vitamin D.

Although some reported association between black skin color and lower serum concentrations of vitamin $D[9,32]$ in our study this relationship was not observed. It is possible that in an area of low socioeconomic insertion black and white live under similar living conditions, which do not favor distinctions among the determinants of deficiency of this vitamin.

Furthermore, another point to add is that, when the dietary intake of vitamin D is low, a major source of this vitamin is exposure to sunlight. In Brazil, the intake of vitamin D is low and the small quantities available in fortified foods are insufficient to meet the physiological needs of vitamin D in the human body [33]. Moreover, exposure to sunlight without sunscreen use has been strongly discouraged by dermatologists [33], this practice may contribute to the occurrence of vitamin D deficiency.

A possible explanation for the relationship between vitamin $\mathrm{D}$ deficiency and commuting to work by motor vehicle is the ability of decreasing the opportunity for the pregnant woman's exposure to sunlight. Another hypothesis is that women with a lower socioeconomic level, who usually walk to work, perform longer walks while exposed to the sun. This condition may favor the photoproduction of vitamin $\mathrm{D}$ and the prevention of the deficiency of this vitamin.

In regards to the environmental factors, it was observed in this study that in winter the women had a higher prevalence of vitamin $\mathrm{D}$ deficiency and higher concentrations of this vitamin during the summer and fall. In such seasons, the activation of the 7dehydrocholesterol in the skin, the initial precursor of vitamin D, is sharper, due to the increasing availability of sunlight and the intensity of the ultraviolet rays.

Thus, low-latitude regions, such as the town in Bahia (latitude $12^{\circ}$ and longitude $39^{\circ}$ ) present a higher availability of sunlight and thus a higher incidence of UV radiation, which can promote the cutaneous of vitamin D. However, reduced serum concentrations of vitamin D among pregnant women were found in fall. This trend of 
a high prevalence of vitamin D deficiency is found in a study conducted in Spain [26]. These results identified in previous studies may suggest that inadequate concentrations are also influenced by factors of a socioeconomic and cultural nature.

On the other hand, one should consider that winter per se is a major risk factor for vitamin D deficiency. Research conducted with adults in São Paulo [18], after winter, reported an average concentration of $25(\mathrm{OH}) \mathrm{D}_{3}$ of $21.4 \mathrm{ng} / \mathrm{ml}$ and $77.4 \%$ of the individuals had presented serum 25 vitamin D $30 \mathrm{ng} / \mathrm{ml}$. In that study, 209 volunteers were submitted, during the summer, to a second assessment of serum concentrations of vitamin D, identifying an average increase of $10.6 \mathrm{ng} / \mathrm{ml}$ (3.7-19.3) in the concentration of $25(\mathrm{OH}) \mathrm{D}$ and a significant reduction in the prevalence of 25 vitamin $\mathrm{D}<30 \mathrm{ng} / \mathrm{ml}[18]$.

This study is one of the first to analyze the vitamin D concetrations in healthy pregnant women in Brazil, using as scenario a city with a high solar incidence. We found that vitamin D deficiency was associated with unmarried marital status, exposure of only the face and hands to the sun, the winter season and commuting to work by motor vehicles. We recommend the development of longitudinal studies based on representative samples of the population, involving participants with different sociodemographic and cultural conditions, in order to identify the variation in vitamin D concentrations among pregnant women according to different epidemiological contexts of the country. In addition, the need for nutritional guidelines on the consumption of foods rich in vitamin $\mathrm{D}$ and lifestyle habits that enable increased sun exposure during pregnancy is highlighted. However, the monitoring of vitamin D levels during pregnancy is necessary, especially in winter and in pregnant women with higher socioeconomic conditions, in order to contribute to the correction of deficiencies and negative implications for maternal-infant health.

\section{Funding}

DB Santos had Financial support by the Brazilian National Research Council (CNPq) - project nos. 481509/2012-7: Factors of nutritional and genetic risk during pregnancy associated with low birth weight/prematurity; M Pereira-Santos had financial support by Coordination of Improvement of Higher Education Personnel (CAPES) for granting scholarship during the Masters at the Graduate Program in Food, Nutrition and Health, in School of Nutrition of UFBA, Bahia, Brazil.

\section{References}

[1] Mulligan ML, Felton SK, Riek AE, Bernal-Mizrachi C, et al. Implications of vitamin D deficiency in pregnancy and lactation. Am J Obstet Gynecol 2010;202(5). 429.e1-9.

[2] Liu NQ Hewison M. Vitamin D the placenta and pregnancy. Arch Biochem Biophys 2012;523(1):37-47.

[3] Leffelaar ER, Vrijkotte TG, van Eijsden M. Maternal early pregnancy vitamin D status in relation to fetal and neonatal growth: results of the multi-ethnic Amsterdam Born Children and their Development cohort. Br J Nutr 2010;104:108-17.

[4] Wei SQ Qi HP, Luo ZC, Fraser WD. Maternal vitamin D status and adverse pregnancy outcomes: a systematic review and meta-analysis. J Matern Fetal Neonatal Med 2013;26(9):889-99.

[5] Aghajafari F, Nagulesapillai T, Ronksley PE, Resistente SC, O'Beirne M, Rabi DM. Association between maternal serum 25-hydroxyvitamin D level and pregnancy and neonatal outcomes: systematic review and meta-analysis of observational studies. BMJ 2013;346:f1169.

[6] Weisse K, Winkler S, Hirche F, Herberth G, Hinz D, Bauer M, et al. Maternal and newborn vitamin D status and its impact on food allergy development in the German LINA cohort study. Allergy 2013;68(2):220-8.
[7] Han Y-Y, Blatter J, Brehm JM, Forno E, Litonjua AA, Celedón JC. Diet and asthma: vitamins and methyl donors. Lancet Respir Med 2013;1(10):813-22. https://doi.org/10.1016/S2213-2600(13)70126-7.

[8] Pludowski P, Holick MF, Pilz S, Wagner CL, Hollis BW, Grant WB, et al. Vitamin $\mathrm{nD}$ effects on musculoskeletal health, immunity, autoimmunity, cardiovascular disease, cancer, fertility, pregnancy, dementia and mortality- a review of recent evidence. Autoimmun Rev 2013 Aug;12(10):976-89.

[9] Dawodu A, Wagner CL. Mother-child vitamin D deficiency: an international perspective. Arch Dis Child 2007;92(9):737-40.

[10] Pereira-Santos M, Costa PR, Assis AM, Santos CA, Santos DB. Obesity and vitamin D deficiency: a systematic review and meta-analysis. Obes Rev 2015;16(4):341-9.

[11] Bodnar LM, Catov JM, Roberts JM, Simhan HN. Prepregnancy obesity predicts poor vitamin D status in mothers and their neonates. J Nutr 2007;137(11): 2437-42.

[12] Van den Berg G, van Eijsden M, Vrijkotte TG, Gemke RJ. Suboptimal maternal vitamin D status and low education level as determinants of small-forgestational-age birth weight. Eur J Nutr 2013;52(1):273-9.

[13] Bener A, Al-Hamaq AO, Saleh NM. Association between vitamin D insufficiency and adverse pregnancy outcome: global comparisons. Int J Womens Health 2013;4(5):523-31.

[14] Jääskeläinen T, Knekt P, Marniemi J, Sares-Jäske L, Männistö S, Heliövaara M, et al. Vitamin D status is associated with sociodemographic factors, lifestyle and metabolic health. Eur J Nutr 2013;52(2):513-22.

[15] Holick MF. Vitamin D deficiency. N Engl J Med 2007;357:266-81.

[16] Tsiaras WG, Weinstock MA. Factors influencing vitamin D status. Acta Derm Venereol 2011;91:115-24.

[17] Martini LA, Verly Jr E, Marchioni DM, Fisberg RM. Prevalence and correlates of calcium and vitamin D status adequacy in adolescents, adults, and elderly from the Health Survey São Paulo. Nutrition 2013;29:845-50.

[18] Unger MD, Cuppari L, Titan SM, Magalhães MCT, Sassaki AL, Reis LM, et al. Vitamin D status in a sunny country: where has the sun gone? Clin Nutr 2010;29(6):784-8.

[19] Palacios C, Gonzalez L. Is vitamin D deficiency a major global public health problem? J Steroid Biochem Mol Biol 2014;144(Pt A):138-45. https://doi.org/ 10.1016/j.jsbmb.2013.11.003.

[20] Pereira EB, Martins FR, Abreu SC, Rüther R. Atlas Brasileiro de Energia Solar. São José dos Campos: INPE; 2006.

[21] Atlas Solarimétrico do Brasil: banco de dados solarimétricos. Recife: Universitaria da UFPE; 2000.

[22] Lohman TG, Roche AF, Martorell R. Anthropometric standardization reference manual. Illinois: Human Kinetics Books; 1988. p. 1-12.

[23] Holick MF, Binkley NC, Bischoff-Ferrari HA, Gordon CM, Hanley DA, Heaney RP, et al. Evaluation, treatment, and prevention of vitamin D deficiency: an Endocrine Society clinical practice guideline. J Clin Endocrinol Metab 2011;96:1911-3.

[24] Hosmer D, Lemeshow S. Applied logistic regression. 2nd ed. New York: John Wiley; 2000.

[25] Magnus MC, Stene LC, Håberg SE, Nafstad P, Stigum H, London SJ, et al. Prospective study of maternal mid-pregnancy 25-hydroxyvitamin D level and early childhood respiratory disorders. Paediatr Perinat Epidemiol 2013;27(6): $532-41$.

[26] Rodríguez-Dehli AC, Galán IR, Fernández-Somoano A, Navarrete-Muñoz EM, Espada M, Vioque J, et al. Prevalencia de deficiencia e insuficiencia de vitamina D y factores asociados en mujeres embarazadas del norte de España. Nutr Hosp 2015;1;31(4):1633-40. https://doi.org/10.3305/nh.2015.31.4.8448.

[27] Vandevijvere S, Amsalkhir S, Van Oyen H, Moreno-Reyes R. High prevalence of vitamin D deficiency in pregnant women: a national cross-sectional survey. PLoS One 2012;7(8), e43868.

[28] Jao J, Freimanis L, Mussi-Pinhata MM, Cohen RA, Monteiro JP, Cruz ML, et al. NISDI LILAC Protocol. Low vitamin D status among pregnant Latin American and Caribbean women with HIV Infection. Int J Gynaecol Obstet 2015. pii: S0020-7292(15) 00184-00188.

[29] Weinert LS, Reichelt AJ, Schmitt LR, Boff R, Oppermann ML, Camargo JL, et al. Serum vitamin D insufficiency is related to blood pressure in diabetic pregnancy. Am J Hypertens 2014;27(10):1316-20.

[30] Oliveira RM, Novaes JF, Azeredo LM, Cândido AP, Leite IC. Association of vitamin D insufficiency with adiposity and metabolic disorders in Brazilian adolescents. Public Health Nutr 2014;17(4):787-94.

[31] Hintzpeter B, Mensink GB, Thierfelder W, Muller MJ, Scheidt-Nave C. Vitamin D status and health correlates among German adults. Eur J Clin Nutr 2008;62: 1079-89.

[32] Luque-Fernandez MA, Gelaye B, VanderWeele T, Ferre C, Siega-Riz AM, Holzman C, et al. Seasonal variation of 25-hydroxyvitamin D among nonHispanic black and white pregnant women from three US pregnancy cohorts. Paediatr Perinat Epidemiol 2014 Mar;28(2):166-76.

[33] Peters BS, dos Santos LC, Fisberg M, Wood RJ, Martini LA. Prevalence of vitamin D insufficiency in Brazilian adolescents. Ann Nutr Metab 2009;54(1): 15-20. 